\title{
Malignant Ear Neoplasm
}

National Cancer Institute

\section{Source}

National Cancer Institute. Malignant Ear Neoplasm. NCI Thesaurus. Code C9337.

A malignant neoplasm that affects the ear. Representative examples include ceruminous adenocarcinoma and squamous cell carcinoma of the external ear and adenocarcinoma of the middle ear. 